\title{
Influence of exercise-induced maternal stress on fetal outcome in Wistar rats: inter-generational effects
}

\author{
BY MARTINA L. PINTO AND P. S. SHETTY* \\ Nutrition Research Centre, Department of Physiology, St. John's Medical College, \\ Bangalore-560 034, India
}

(Received 25 August 1994 - Accepted 5 October 1994)

\begin{abstract}
The effects of physical activity during pregnancy and lactation on the fetal outcome and the growth of pups was studied in Wistar rats $(n$ 144). Rats were trained to swim for 2 h every day, $6 \mathrm{~d} /$ week through pre-pregnancy, pregnancy and lactation. Maternal exercise during pregnancy, despite the dams having ad lib. access to food, resulted in low-birth-weight pups $(5.6$ (SD 0.7) $\mathrm{g} ; n 178$ in exercised dams $v$. 6.2 (SD 0.8$) \mathrm{g} ; \boldsymbol{n} 238$ in sedentary dams). Maternal exercise continued through lactation exaggerated further the growth retardation of these pups (30.0 (SD 4.7) $\mathrm{g} ; n \mathbf{n}$ in exercised dams v. 36.0 (SD 6.9) g; $n 126$ in sedentary dams). The effects of maternal exercise during pregnancy and lactation studied over two successive generations revealed a reduction in the growth rates of the second generation progeny of both exercised (5.3 (SD 0.9) $\mathrm{g} ; n \mathbf{n} 125$ at birth and 25.1 (SD 6.8) g; $n 54$ at weaning) and sedentary rats $(6.0$ (SD 0.2) $g ; n 110$ at birth and 31.3 (SD 4.3) $\mathrm{g}$ at weaning) born to first-generation exercised rats. While slower growth in the former indicates a cumulative effect of exercise stress over two generations, that of the latter indicates that the generational effects are manifest even though the dams of the $F_{1}$ generation were not exposed to exercise stress during pregnancy and lactation. These findings suggest that the adverse effect of maternal exercise during pregnancy and lactation on fetal outcome in one generation is transferred to the subsequent generation.
\end{abstract}

Exercise: Pregnancy: Lactation: Birth weight: Growth: Rat

Exercise increases energy expenditure and exercise or physical work during pregnancy is thought to be a predisposing factor to premature labour, low-birth-weight babies and increased infant mortality rates (Naeye \& Peters, 1982). Adverse effects of maternal exercise during pregnancy and lactation on fetal outcome and postnatal growth in animals have been reported (Terada, 1974; Levitsky et al., 1977; Parizkova, 1979; Jenkins \& Ciconne, 1980; Uriu-Hare et al. 1989). A preliminary study conducted in our laboratory indicated that the adverse effects of maternal exercise during pregnancy and lactation on fetal and pup growth last beyond the weaning period causing irreversible growth retardation in rats (Pinto \& Shetty, 1990). We therefore hypothesized that the deleterious effects of maternal exercise during pregnancy and lactation on the offspring may influence the subsequent generations.

Inter-generational effects of maternal malnutrition during pregnancy have been widely reported in animals (Cowley \& Griesel, 1966; McLeod et al. 1972; Stewart et al. 1975; Galler, 1981). The effects of anxiety-induced stress in rats during pregnancy have been reported to last over succeeding generations (Pollard, 1986). Studies involving the persistent effects of maternal exercise during pregnancy and lactation through generations have not been reported to date. The present study was designed to observe the adverse

* For reprints.

$\dagger$ Present address: Human Nutrition Unit, Department of Public Health and Policy, London School of Hygiene and Tropical Medicine, 2 Taviton Street, London WC1H 0BT. 
effects of exercise in rats, over two generations. The findings from this study may have implications for chronically undernourished, physically hard-working pregnant and lactating women and their children who form a large proportion of the world's population. They also provide indirect support for the interesting hypothesis on the fetal origins of adult disease and the long-term consequences of pre- and post-natal environmental influences (Barker, 1990).

\section{MATERIALS AND METHODS}

\section{Animals and housing}

Albino strain Wistar rats obtained from the National Institute of Nutrition, inbred for several generations, were used for the study. Animals were housed individually in polyethylene cages and were exposed to a $12 \mathrm{~h}$ light and dark cycle, in an animal house maintained at minimum and maximum temperatures of $24.9^{\circ}$ and $28 \cdot 5^{\circ}$ respectively.

\section{Diet}

Twelve-week-old female virgin rats weighing between 145 and $155 \mathrm{~g}$ were chosen. The rats were given free access to water and food which was a powdered diet comprising $(\mathrm{g} / \mathrm{kg})$ : protein 170 , carbohydrate 530 , fat 140 , salts 40 and water 130 , prepared in our laboratory (Rao, 1980). The powder was mixed with water in the ratio 3:1, the energy value being $12.2 \mathrm{~kJ} / \mathrm{g}$ wet food. Following a $5 \mathrm{~d}$ adjustment period the rats were assigned to two groups; group 1, non-exercised or sedentary rats $\left(F_{0} S E D\right)$ and group 2, exercise-trained rats $\left(F_{0} E X\right)$. Rats in the sedentary group had free access to food whilst their counterparts were exercising.

\section{Exercise protocol}

The exercise protocol was a modified version of that described by Treadway \& Lederman (1986), which consisted of $2 \mathrm{~h}$ continuous, forced swimming every day, $6 \mathrm{~d} /$ week. The protocol complied with the requirements given by the Committee on Care and Use of Laboratory Animals (1985). Training was carried out in two phases: phase 1 included the first $10 \mathrm{~d}$ during which the rats were gradually and progressively trained to swim for increasing units of $15 \mathrm{~min} / \mathrm{d}$, i.e. rats were required to swim for $15 \mathrm{~min}$ on day $1,30 \mathrm{~min}$ on day $2 ; 45$ min on day 3 and so on, until they were able to swim for two continuous hours every day. During phase 2 the rats were exercised for $2 \mathrm{~h}$ every day, $6 \mathrm{~d} /$ week. The rats were made to swim in a tank measuring $84 \times 42 \times 74 \mathrm{~cm}$ (length $\times$ width $\times$ depth), with a capacity of approximately 250 litres water which was maintained at a temperature of $30 \pm 2^{\circ}$.

Following 30-35 d exercise training the rats in both groups were allowed to mate. Female rats to be mated were housed overnight with male rats on a $1: 1$ (female:male) basis. The finding of a sperm-positive vaginal smear the following morning confirmed pregnancy and that day was considered as day zero of pregnancy. Rats that failed to conceive within a week were excluded from the study. While rats in group $1\left(F_{0} S E D\right)$ remained sedentary, those in group $2\left(\mathrm{~F}_{0} \mathrm{EX}\right)$ continued to exercise for $2 \mathrm{~h} / \mathrm{d}$ until day 19 of pregnancy. On the day the rats delivered the pups $\left(F_{1}\right.$ generation), birth weights were recorded. The litters were culled to eight per dam and this litter size was maintained throughout lactation. Maternal exercise was resumed from day 3 until day 21 of lactation. To maintain a constant time available for nursing in both the sedentary and exercised groups the pups of the sedentary rats were separated from their mothers for a period of $2.5 \mathrm{~h}$ when the exercised dams swam. Body weight of the pups was monitored during the pre-weaning period. The pups were weaned on day 22 of lactation following which the pups had free access to food and water. 
Post-weaning body-weight changes in the pups of the $F_{1}$ generation were recorded in both groups. When they were 12 weeks old the pups born to dams in group $F_{0}$ SED were further assigned to either a sedentary (group $F_{1}$ SED-sed) or exercised (group $F_{1}$ SED-ex) category and those born to dams of group $F_{0}$ EX were also sub-divided into sedentary (group $F_{1}$ EX-sed) and exercised (group $F_{1}$ EX-ex) categories.

Rats in the exercised groups (both group $F_{1}$ SED-ex and group $F_{1}$ EX-ex) were exercisetrained during pre-pregnancy, allowed to mate and the exercise was continued until day 19 of pregnancy (exercise protocol described earlier). Following delivery of the pups ( $\mathrm{F}_{2}$ generation) the birth weight was recorded and litters were culled to eight per dam. The dams were exercised from day 3 of lactation until day 22. Thus rats which were already exposed to pre-natal and post-natal stress (by subjecting their mothers to forced exercise both during pregnancy and lactation) were further exercised through pregnancy and lactation. Rats in group $F_{1}$ SED-sed and group $F_{1}$ EX-sed however remained sedentary through pre-pregnancy, pregnancy and lactation. The growth rate of the pups in the $F_{2}$ generation was monitored from birth until $90 \mathrm{~d}$ of age. The pups were weaned on day 22 of lactation and provided with free access to the diet following weaning.

\section{Statistical analysis}

Data were analysed by one-way ANOVA using the SPSS/PC + program (SPSS, SPSS/PC advanced statistics $V_{2}$, Chicago, IL, USA). Means obtained from the analysis were compared by the Student's-Newman-Keuls (SNK) multiple comparison test, at a $5 \%$ level of probability. Correlation coefficients for birth weight with maternal pre-pregnancy weight as well as pup growth with birth weight were computed.

\section{RESULTS \\ $F_{1}$ generation}

Birth weight of the pups of exercised dams $\left(\mathrm{F}_{0} \mathrm{EX}\right)$ was significantly lower $(10 \%)$ than that of the sedentary dams $\left(F_{0} S E D\right)$ despite both groups having free access to food (Table 1). The energy intake of the $F_{0}$ EX group $(224.1 \mathrm{~kJ} / \mathrm{d})$ was significantly higher $(P<0.002)$ than that of the $F_{0}$ SED group $(191.8 \mathrm{~kJ} / \mathrm{d}$ ) during pregnancy (Table 2). The litters of exercised dams grew more slowly and had significantly lower body weights than those of the sedentary rats at comparable ages (Table 3 ). The weight deficit observed in these pups at birth was further enhanced by the maternal exercise during lactation; the total reduction in weight at weaning was $15 \%$ in males and $18 \%$ in females. This was followed by a phase of 'catch-up' growth represented by near comparable body weights, at 7-8 d post-weaning. Body weights of the pups of exercised rats nevertheless continued to be lower $(9 \%$ deficit in both males and females) than those of sedentary rats on follow-up at $90 \mathrm{~d}$ of age (Tables 1 and 3).

\section{$F_{2}$ generation}

The pups in the $F_{2}$, or second, generation born of sedentary dams (group $F_{1}$ SED-sed) had body weights similar to those of the $F_{1}$ generation pups born to sedentary rats (group $F_{0}$ SED). The second generation or $F_{2}$ litter of exercised dams (group $F_{1}$ SED-ex) which were also born of sedentary rats showed a growth pattern similar to that of the $F_{1}$ generation litter of the exercised dams (group $\mathrm{F}_{0} \mathrm{EX}$ ) (Table 1).

Despite being sedentary through pre-pregnancy, pregnancy and lactation, the rats (group $\mathrm{F}_{1} \mathrm{EX}$-sed) born of exercised dams (group $\mathrm{F}_{0} \mathrm{EX}$ ) gave birth to pups with low body weight. The weight reduction (3\% in males and $5 \%$ in females) at birth was further enhanced at weaning ( $9 \%$ in males and $15 \%$ in females) compared with that of the $F_{1}$ generation litter 
Table 1. Effects of maternal exercise during pregnancy and lactation on birth weight and the consequent growth and weight gain in pre-weaning rat pups§

(Mean values and standard deviations)

\begin{tabular}{|c|c|c|c|c|c|c|c|c|c|c|}
\hline \multirow[b]{3}{*}{ Group } & \multicolumn{10}{|c|}{ Weight (g) } \\
\hline & \multicolumn{2}{|c|}{ Birth weight } & \multicolumn{2}{|c|}{$4 d$} & \multicolumn{2}{|c|}{$10 \mathrm{~d}$} & \multicolumn{2}{|c|}{$16 d$} & \multicolumn{2}{|c|}{$22 \mathrm{~d}$} \\
\hline & Mean & SD . & Mean & SD & Mean & SD & Mean & SD & Mean & SD \\
\hline \multicolumn{11}{|l|}{ Generation 1} \\
\hline$F_{1}$ SED & $6 \cdot 2$ & 0.8 & $9.8 \dagger$ & 2.0 & $16.9 \dagger$ & $2 \cdot 1$ & $25 \cdot 3 \dagger$ & 3.0 & \multirow{2}{*}{\multicolumn{2}{|c|}{${ }_{126}^{36-0 \dagger} 6.9$}} \\
\hline & \multicolumn{2}{|c|}{238} & \multicolumn{2}{|c|}{91} & & & \multicolumn{2}{|c|}{214} & & \\
\hline $\mathrm{F}_{1} \mathrm{EX}$ & \multicolumn{2}{|c|}{${ }_{178}^{5.6 * \pm} 0.7$} & $7 \cdot 7^{*}$ & 87 & $14 \cdot 5^{*}$ & $2 \cdot 0$ & \multicolumn{2}{|c|}{${ }_{163}^{21.5^{*} \ddagger} 2 \cdot 6$} & \multicolumn{2}{|c|}{$\frac{30-0^{*} \ddagger}{78} 4 \cdot 7$} \\
\hline \multicolumn{11}{|l|}{ Generation 2} \\
\hline $\mathrm{F}_{2}$ SED-sed & \multicolumn{2}{|c|}{$6.275^{0.5}$} & \multicolumn{2}{|c|}{$9 \cdot 6 t_{75}$} & & 1.5 & \multicolumn{2}{|c|}{$24.9 \dagger_{75} 2 \cdot 2$} & \multicolumn{2}{|c|}{$35 \cdot 4 \uparrow_{75} 4 \cdot 5$} \\
\hline $\mathrm{F}_{2}$ SED-ex & \multicolumn{2}{|c|}{$5.8 * \pm 0.5$} & \multicolumn{2}{|c|}{${ }^{*}{ }_{55} 0.6$} & $14 \cdot 4^{*}$ & $2 \cdot 3$ & $20 \cdot 2^{*}$ & $2 \cdot 6$ & \multicolumn{2}{|c|}{$30 \cdot 2 *+5 \cdot 1$} \\
\hline$\underset{n}{\mathrm{~F}_{2}} \mathrm{EX}$-sed & \multicolumn{2}{|c|}{$6.0110^{0.2}$} & \multicolumn{2}{|c|}{${ }^{7.8}{ }_{42}^{1.2}$} & \multicolumn{2}{|c|}{46} & & $3 \cdot 1$ & 70 & $4 \cdot 3$ \\
\hline$\underset{n}{\mathrm{~F}_{2}} \underset{n}{\mathrm{EX}-\mathrm{ex}}$ & \multicolumn{2}{|c|}{${ }_{125^{5.3 *}}^{0.9}$} & \multicolumn{2}{|c|}{97} & $10.9 *$ & 1.9 & $18 \cdot 7^{*}$ & $3 \cdot 8$ & 54 & 6.8 \\
\hline
\end{tabular}

* Mean values were significantly different from those of the corresponding sedentary group, $P<0.05$.

$\dagger$ Mean values were significantly different from those of the $\mathrm{F}_{2}$ EX-sed group, $P<0.05$.

$¥$ Mean values were significantly different from those of the $F_{2}$ EX-ex group, $P<0.05$.

$\S$ For details of procedures, see pp. 646-647.

Table 2. Comparisons of weight gain and energy intake of sedentary (SED) rats compared with that of exercised $(E X)$ rats during pregnancy and lactation $\dagger$

(Mean values and standard deviations)

\begin{tabular}{|c|c|c|c|c|}
\hline \multirow[b]{2}{*}{ Group } & \multicolumn{2}{|c|}{ Pregnancy } & \multicolumn{2}{|c|}{ Lactation } \\
\hline & $\begin{array}{l}\text { Weight gain } \\
(\mathrm{g})\end{array}$ & $\begin{array}{l}\text { Energy intake } \\
(\mathrm{kJ} / \mathrm{d})\end{array}$ & $\begin{array}{l}\text { Weight loss } \\
\text { (g) }\end{array}$ & $\begin{array}{l}\text { Energy intake } \\
(\mathbf{k J} / \mathbf{d})\end{array}$ \\
\hline$F_{0}$ SED & 93.4 & 191.8 & 21.4 & $332 \cdot 2$ \\
\hline SD & 13.9 & 30.0 & $9 \cdot 1$ & $19 \cdot 2$ \\
\hline & 17 & 17 & 16 & 16 \\
\hline$F_{0}$ EX & $100 \cdot 2$ & $224 \cdot 1^{*}$ & $3.9 *$ & $375 \cdot 7^{*}$ \\
\hline SD & $13 \cdot 4$ & $23 \cdot 2$ & $9 \cdot 7$ & $40 \cdot 9$ \\
\hline$n$ & 15 & 15 & 17 & 17 \\
\hline
\end{tabular}

* Mean values were significantly different from those of the sedentary group, $P<0.05$ (unpaired $t$ test).

$\uparrow$ For details of procedures, see pp. 646-647.

of sedentary dams. Although there was 'catch-up' growth in the immediate post-weaning period, there appeared to be a permanent weight deficit as evidenced by the reduced weight gain (7\% weight deficit in males and $11 \%$ weight deficit in females) at 3 months of age compared with that of the litter of sedentary dams $\left(F_{1}\right.$ SED) (Table 3).

A weight deficit (16\% in males and $15 \%$ in females) at birth was observed in the pups of exercised rats of group $F_{1}$ EX-ex compared with the litters of sedentary dams, i.e. group 
Table 3. Effects of maternal exercise during pregnancy and lactation on the weight gain of pups during the post-weaning period over two successive generations\$

(Mean values and standard deviations)

\begin{tabular}{|c|c|c|c|c|c|c|}
\hline \multirow[b]{3}{*}{ Group } & \multicolumn{6}{|c|}{ Weight (g) } \\
\hline & \multicolumn{2}{|c|}{$30 \mathrm{~d}$} & \multicolumn{2}{|c|}{$60 d$} & \multicolumn{2}{|c|}{$90 \mathrm{~d}$} \\
\hline & Male & Female & Male & Female & Male & Female \\
\hline \multicolumn{7}{|l|}{ Generation 1} \\
\hline$F_{1}$ SED & $55 \cdot 7$ & $53 \cdot 1$ & $151.9 \dagger$ & $121.0 \dagger$ & $224.4 \dagger$ & $156.4 \dagger$ \\
\hline SD & $12 \cdot 3$ & $12 \cdot 3$ & $21 \cdot 1$ & $15 \cdot 0$ & $26 \cdot 8$ & $16 \cdot 9$ \\
\hline$n$ & 67 & 85 & 72 & 82 & 62 & 82 \\
\hline $\mathrm{F}_{1} \mathrm{EX}$ & $54.9 \ddagger$ & $51.0 \ddagger$ & $134 \cdot 5^{*}+$ & $108 \cdot 6^{*}$ & $203 \cdot 3 * t$ & $142 \cdot 0 * \ddagger$ \\
\hline SD & $6 \cdot 6^{\circ}$ & $7 \cdot 4$ & $22 \cdot 2$ & $14 \cdot 2$ & $30 \cdot 3$ & $13 \cdot 6$ \\
\hline$n$ & 36 & 51 & 26 & 57 & 28 & 58 \\
\hline \multicolumn{7}{|l|}{ Generation 2} \\
\hline$F_{2}$ SED-sed & $57 \cdot 2$ & $51 \cdot 2$ & $148 \cdot 0 \dagger$ & $119.7 \dagger$ & $222 \cdot 1 \dagger$ & $154 \cdot 4 \dagger$ \\
\hline $\mathrm{SD}$ & $8 \cdot 2$ & $8 \cdot 3$ & $11 \cdot 5$ & 9.9 & 19.9 & $11 \cdot 2$ \\
\hline$n$ & 35 & 40 & 35 & 41 & 35 & 41 \\
\hline$F_{2}$ SED-ex & $56-7 \ddagger$ & $50 \cdot 4 \ddagger$ & $134 \cdot 5^{*} t$ & $102 \cdot 4^{*}$ & $199 \cdot 7^{*} \ddagger$ & $137 \cdot 6 * \ddagger$ \\
\hline $\mathrm{SD}$ & 6.5 & $9 \cdot 1^{\top}$ & $22 \cdot 2$ & $12 \cdot 6$ & $28 \cdot 3$ & $13 \cdot 7$ \\
\hline$n$ & 26 & 29 & 26 & 29 & 26 & 29 \\
\hline$F_{2}$ EX-sed & $51 \cdot 1$ & $48 \cdot 2$ & $133-5$ & $107 \cdot 4$ & $207 \cdot 4$ & 138.6 \\
\hline SD & $7 \cdot 9$ & $8 \cdot 2$ & $20 \cdot 3$ & 14.9 & $26 \cdot 4$ & 15.9 \\
\hline$n$ & 28 & 41 & 35 & 35 & 31 & 27 \\
\hline$F_{2}$ EX-ex & $47 \cdot 5$ & $44 \cdot 0$ & $117 \cdot 9^{*}$ & 101.9 & $161 \cdot 2^{*}$ & $125 \cdot 1^{*}$ \\
\hline SD & $8 \cdot 3$ & $8 \cdot 3$ & $17 \cdot 9$ & $6 \cdot 3$ & $33 \cdot 5$ & 14.9 \\
\hline$n$ & 21 & 29 & 25 & 31 & 27 & 32 \\
\hline
\end{tabular}

SED, sedentary; EX, exercise-trained.

* Mean values were significantly different from those of the corresponding sedentary groups, $P<0 \cdot 05$.

+ Mean values were significantly different from those of the $\mathrm{F}_{2}$ EX-sed group, $P<0.05$.

$\ddagger$ Mean values were significantly different from those of the $\mathrm{F}_{2}$ EX-ex group, $P<0.05$.

$\S$ For details of procedures, see pp. 646-647.

$F_{0}$ SED. The growth rate of these pups was significantly lower than that of the normal pups $\left(F_{1} S E D\right)$, the total weight reduction at weaning being $29 \%$ in males and $31 \%$ in females. The 'catch-up' growth observed in these pups following weaning however was not adequate to offset the permanent weight deficit (28\% in males and $20 \%$ in females) observed at 3 months of age (Table 3 ).

Table 4 presents maternal pre-pregnancy weights in all the six groups of rats studied. Exercise training in the rats born of sedentary dams in both $F_{1}$ and $F_{2}$ generations did not affect their weight gain during exercise, as evidenced by the comparable weight gain at the end of the pre-pregnant exercise-training period. The rats born of exercised dams (groups $F_{1}$ EX-sed and $F_{1}$ EX-ex) initially had lower body weights compared with the other groups and pre-pregnant exercise training further reduced the rate of weight gain. Rats born of exercised dams thus started pregnancy with markedly lowered body weights.

Birth weight was significantly correlated $(r 0.21, n 781, P<0.0001)$ with maternal prepregnancy weight when all the six groups were treated as a whole. Although the birth weights of the $F_{1}$ generation pups did not correlate significantly with their maternal prepregnancy weights, those of the pups in the $\mathrm{F}_{2}$ generation and their maternal pre-pregnancy weights were correlated significantly $(r 0.29, n 365, P<0.0001)$. However, when the correlations were made separately between the exercised and sedentary groups in the $F_{2}$ 
Table 4. Comparisons of weight gained by sedentary rats over a period of $30 \mathrm{~d}$ compared with the weight gained by exercised pre-pregnant rats over the same interval

(Mean values and standard deviations)

\begin{tabular}{|c|c|c|c|}
\hline Group $\ddagger$ & $\begin{array}{l}\text { Weight before } \\
\text { exercise } \\
\text { training } \\
\text { (g) }\end{array}$ & $\begin{array}{l}\text { Weight after } \\
\text { exercise } \\
\text { training } \\
\text { (g) }\end{array}$ & $\begin{array}{l}\text { Weight gain } \\
\text { (g) }\end{array}$ \\
\hline SED rats & $161 \cdot 7^{\mathrm{a}}$ & $185 \cdot 6^{\mathrm{a}} \dagger$ & $23 \cdot 8^{\mathrm{a}}$ \\
\hline SD & $8 \cdot 2$ & $15 \cdot 9$ & 12.5 \\
\hline$n$ & - & 16 & - \\
\hline EX rats & $162 \cdot 3^{a}$ & $185 \cdot 9^{a}$ & $23 \cdot 6^{\mathrm{a}}$ \\
\hline SD & 8.4 & $9 \cdot 1$ & $5 \cdot 1$ \\
\hline$n$ & - & 12 & - \\
\hline SED-sed rats & $162 \cdot 1^{\mathrm{a}}$ & $185 \cdot 1^{a}+$ & $23 \cdot 0^{\mathrm{a}}$ \\
\hline SD & 8.7 & $17 \cdot 1$ & $13 \cdot 1$ \\
\hline$n$ & - & 14 & - \\
\hline SED-ex rats & $162 \cdot 4^{a}$ & $185 \cdot 7^{\mathrm{a}}$ & $23 \cdot 4^{\mathrm{a}}$ \\
\hline SD & $8 \cdot 8$ & $9 \cdot 5$ & $5 \cdot 2$ \\
\hline$n$ & - & 11 & - \\
\hline EX-sed rats & $145 \cdot 6^{b}$ & $165 \cdot 5^{b}+$ & $17 \cdot 5^{b}$ \\
\hline SD & 15.0 & $14 \cdot 6$ & $20-4$ \\
\hline$n$ & - & 19 & - \\
\hline EX-ex rats & $141 \cdot 7^{b}$ & $150 \cdot 2^{c}$ & $8 \cdot 4^{c}$ \\
\hline SD & 7.8 & $9 \cdot 7$ & $12 \cdot 7$ \\
\hline$n$ & - & 19 & - \\
\hline
\end{tabular}

SED, sedentary; EX, exercise-trained.

a,b.c Mean values within a column not sharing a common superscript letter were significantly different, $P<0.05$.

$\uparrow$ Not exercise trained.

₹ For details of groups, see pp. 646-647.

generation the birth weight and the maternal pre-pregnancy weights were closely correlated $\left(r 0.27, n 235, P<0.0001\right.$ ) only in pups born of exercised dams (groups $\mathrm{F}_{1}$ EX-sed and $\mathrm{F}_{1}$ EX-ex).

When all six study groups were considered the pre-weaning pup growth was significantly correlated $(r 0.32, n 458, P<0.0001)$ with birth weight, as was the post-weaning growth with birth weight $(r 0.19, n 473, P<0.0001)$. Neither body weight at weaning $(r 0.07, n 204$, $P<0.3)$ nor post-weaning growth $(r 0.1, n 229, P<0.12)$ of the first generation litter correlated significantly with birth weight. However, in the second generation litter born of exercised dams the birth weight was significantly correlated with pre-weaning growth $(r 0 \cdot 6$, $n 124, P<0.0001)$ as well as the growth thereafter $(r 0.3, n 114, P<0.0001)$.

Maternal exercise over two generations during pregnancy and lactation influenced the pregnancy outcome. Table 5 summarizes the effects of maternal exercise on litter size and litter weight at birth compared with sedentary animals over two generations. Both litter size and litter weight (inclusive of pups dead at birth) were significantly reduced in the case of $F_{1}$ EX-ex dams.

Marked changes in the behavioural pattern were observed during lactation in rats which were pre-natally and post-natally exercised. These rats (groups $F_{1}$ EX-sed and $F_{1}$ EX-ex) were lighter and more aggressive than the normals and cannibalized their offspring. About $50 \%$ of rats in both the groups gave birth to one or two malformed or still-born pups per dam. Of the sedentary rats born of exercised dams (group $F_{1}$ EX-sed), $25 \%$ had 
Table 5. The effect of maternal exercise on pregnancy outcome (litter size and litter weight) in rats over two successive generations*

(Mean values and standard deviations)

\begin{tabular}{|c|c|c|c|c|c|}
\hline \multirow[b]{2}{*}{ Group } & \multicolumn{2}{|c|}{ Litter size } & & \multicolumn{2}{|c|}{ Litter weight $(\mathrm{g}) \dagger$} \\
\hline & Mean & SD & & Mean & SD \\
\hline SED dams & $8 \cdot 5^{a}$ & $1 \cdot 5$ & & $51 \cdot 5^{\mathrm{a}}$ & $7 \cdot 6$ \\
\hline$n$ & & & 37 & & \\
\hline EX dams & $8 \cdot 4^{a}$ & $2 \cdot 8$ & & $46 \cdot 8^{8}$ & 14.8 \\
\hline$n$ & & & 32 & & \\
\hline SED-sed dams & $8 \cdot 3^{a}$ & $1 \cdot 4$ & & $50 \cdot 1^{\mathrm{s}}$ & $7 \cdot 1$ \\
\hline$n$ & & & 24 & & \\
\hline SED-ex dams & $8 \cdot 6^{\mathrm{a}}$ & $1 \cdot 4$ & & $49 \cdot 0^{\mathrm{a}}$ & $14 \cdot 4$ \\
\hline$n$ & & & 18 & & \\
\hline EX-sed dams & $7 \cdot 8^{\mathrm{a}}$ & $1 \cdot 3$ & & $44 \cdot 8^{b}$ & 6.0 \\
\hline$n$ & & & 15 & & \\
\hline EX-es dams & $6 \cdot 6^{b}$ & $2 \cdot 7$ & & $36 \cdot 6^{\mathrm{e}}$ & $15 \cdot 5$ \\
\hline$n$ & & & 18 & & \\
\hline
\end{tabular}

SED, sedentary; EX, exercise-trained.

a,b,c Mean values within a column not sharing a common superscript letter were significantly different, $P<0.05$.

* For details of procedures, see pp. 646-647.

$\dagger$ Total litter weight is inclusive of dead fetuses at birth.

cannibalized their pups during lactation (on days 10,15 and 21). Maximal adverse effects of maternal exercise during pregnancy and lactation were observed in the exercised rats born of exercised dams $\left(\mathrm{F}_{1} \mathrm{EX}\right.$-ex). Of these rats, $16 \%$ cannibalized their pups immediately after birth. Of the dams, $19 \%$ died while exercising during lactation and $39 \%$ of the rats demonstrated infanticide and cannibalism of the offspring.

\section{DISCUSSION}

Despite free access to food, maternal exercise during pregnancy had adverse effects on the birth weight of pups. The intra-uterine growth retardation observed in the present study supports previous findings (Terada, 1974; Levitsky et al. 1977; Uriu-Hare et al. 1989). The competition between maternal exercising muscles and the fetus for substrates may have resulted in a decreased availability of these substrates for normal fetal growth. Smaller placental weights have been reported concomitantly with significantly smaller pup body weights (Gilbert et al. 1981; Nelson et al. 1983). Maternal exercise is known to impair blood flow to the uterus and placenta (Longo et al. 1978) which may account for the lower birth weight of pups in the present study.

The reduced weight gain of the pups during the pre-weaning period may be attributable to a reduction in the quantity or altered quality of milk produced (Treadway et al. 1986). Diminished deposition of maternal subcutaneous fat is known to occur in exercised rats (Mottola et al. 1986). Either the insufficient storage of maternal fat or underdeveloped mammary glands (due to short supply of substrates for normal fat deposition) could result in an inadequate amount of milk production (Mottola et al. 1983). Lactose content is lower in the milk of exercised dams and lactose is known to be necessary for complete intestinal development. Glucose is the primary substrate for lactose production and a decreased 
lactose content in the milk of exercised rats may reflect a decrease in glucose availability to the mammary gland (Treadway et al. 1986). The offspring of exercised rats in the present study were separated from the mothers for about $2.5 \mathrm{~h}$ every day while they were being exercised and this could have affected the time available for milk transfer to the young. However, the slower growth of the pups of exercised rats is unlikely to have been due to the reduced time available for nursing since the pups of sedentary dams were also separated for the same length of time. Despite a 'catch-up' growth phase in the immediate postweaning period when the pups were given unrestricted access to food, the body weights of the pups born to exercised dams were irreversibly reduced. A significant reduction in weight observed in the pups of exercised rats even at 3 months of age suggests that the adverse effect of maternal exercise during pregnancy and lactation on the offspring lasts even beyond the weaning period once the pups grow on a lower trajectory as a result of inadequate lactation during maternal exercise (Treadway et al. 1986). They are unable to attain their full growth potential despite some 'catch-up' growth earlier on.

The most interesting finding in the present study was that the second generation or $F_{2}$ litter of sedentary dams which were born of exercised dams (group $F_{1}$ EX-sed) had a marked lowering of the trajectory of weight gain, suggesting that being sedentary during pregnancy and lactation did not prevent the adverse effects on the growth of pups of rats which were born to exercise-stressed mothers $\left(F_{0} E X\right)$. Swimming during pregnancy and lactation sufficiently stressed the animals, thereby adversely affecting the pre-natal and post-natal growth of pups, which in turn may have resulted in the reduced weight gain of their pups. In rats that are pre- and post-natally stressed (by maternal exercise), even a sedentary life with unrestricted access to food does not help to offset the deleterious effects on the pups, suggesting a definite inter-generational effect of exercise during pregnancy and lactation. The second generation offspring may have been growth-retarded as their mothers' development had been permanently affected by stress in utero. The present findings demonstrate that both intra-uterine and post-natal stress probably lead to longterm physiological changes which are evident in the adult offspring.

The second generation litters $\left(F_{2} E X\right.$-sed and $F_{2}$ EX-ex) of exercised rats (group $\left.F_{1} E X\right)$ which were also subjected to pre-natal and post-natal stress (through maternal exercise) apparently were the worst affected. These litters showed a marked reduction in birth weight which continued well into adulthood with a $28-30 \%$ weight deficit at $90 \mathrm{~d}$ of age, compared with that of their sedentary counterparts $\left(F_{1}\right.$ SED). The stress of maternal exercise superimposed on that of the pre- and post-natal stress thus resulted in low birth weight of the offspring. Birth weight of the pups was positively correlated with maternal prepregnancy weight. Low maternal pre-pregnancy weight in the exercised dams may explain the low birth weight of the second generation litter (whose dams as well as grand-dams had exercised during pregnancy and lactation). This finding may partly explain the incidence of low birth weight, stunted growth, lighter and leaner children of chronically undernourished humans with low pre-pregnant weights and body mass indices, compared with normal children (Naidu et al. 1991).

Cannibalism of the offspring observed in pre- and post-natally stressed rats may also be an index of the stress undergone by these rats. Cannibalism is known to be greater in lighter and leaner dams (Schneider \& Wade, 1989). Dams in both $F_{1}$ EX-sed and $F_{1}$ EX-ex groups started pregnancy with low body weights (Table 4) and remained light throughout the study period. The aggressive behaviour observed in these rats possibly effected by the stress of exercise may explain the high degree of infanticide observed in the present study.

In conclusion, it appears that maternal exercise during pregnancy and lactation influences pregnancy outcome, i.e. litter size, litter weight and birth weights. It also affects the normal growth of pups even if they have ad lib access to food after weaning. Effects of 
maternal exercise appear to be carried over to the next generation even if the dams born to exercised rats are maintained in a sedentary state with ad lib access to food. The intergenerational effects of maternal exercise in rats may contribute to low birth weights and lowered growth profiles in the post-weaning period. These observations seem to provide indirect support for the much discussed hypothesis on the pre-natal influences and infant origins of adult morbidity (Barker, 1990). In this case pre-natal influences result in attaining a lower growth potential in Wistar rats.

Martina L. Pinto was in receipt of a Junior Research Fellowship (IRIS No. 8708530) from the Indian Council of Medical Research.

\section{REFERENCES}

Barker, D. J. P. (1990). The fetal and infant origins of adult disease. British Medical Journal 301, 111.

Committee on Care and Use of Laboratory Animals (1985). Guide for the Care and Use of Laboratory Animals. National Institute of Health Publication no. 85-23. Bethesda, MD: National Research Council/National Institute of Health.

Cowley, J. J. \& Griesel, R. D. (1966). The effect on growth and behaviour of rehabilitating first and second generation low protein fed rats. Animal Behaviour 14, 506-517.

Galler, J. R. (1981). Visual discrimination in rats: the effects of rehabilitation following intergenerational malnutrition. Developmental Psychobiology 14, 229-236.

Gilbert, R. D., Nelson, P. \& Longo, L. (1981). Long term maternal exercise in guinea pigs: effects on fetal growth and development and placental diffusing capacity. American Journal of Obstetrics and Gynecology 140, 123.

Jenkins, R. R. \& Ciconne, C. (1980). Exercise effect during pregnancy on brain nucleic acids of offspring in rats. Archives of Physical Medicine and Rehabilitation 61, 124-127.

Levitsky, L. L., Kimber, A., Marchichow, J. A. \& Uuhara, A. (1977). Metabolic response to fasting in experimental intrauterine growth retardation induced by surgical and nonsurgical maternal stress. Biology of the Neonate 31, 311-315.

Long, L. D., Hewitt, C. W., Lorijn, R. H. W. \& Gilbert, R. D. (1978). To what extent does maternal exercise affect fetal oxygenation and uterine blood flow? Federation Proceedings 37, 905.

McLeod, K. I., Goldrick, B. B. \& Whyte, H. M. (1972). The effect of maternal malnutrition on the progeny in the rat: studies on growth, body composition and organ cellularity in first and second generation progeny. Australian Journal of Biology and Medical Science 50, 435-446.

Mottola, M. F., Bagnall, K. M., Belcastra, A. N., Foster, J. \& Secord, D. (1986). The effects of strenuous maternal exercise during gestation on maternal body composition in rats. Journal of Anatomy 148, 65-75.

Mottola, M. F., Bagnall, K. M. \& McFadden, K. D. (1983). The effects of maternal exercise on developing rat fetuses. British Journal of Sports Medicine 17, 117-121.

Naeye, R. L. \& Peters, E. C. (1982). Working during pregnancy: effects on the fetus. Pediatrics 69, 724-727.

Naidu, A. N., Neela, J. \& Rao, N. P. (1991). Maternal body mass index and birth weight. Nutrition News NIN Hyderabad 12, 2-3.

Nelson, P. S., Gilbert, R. D. \& Longo, L. D. (1983). Fetal growth and placental diffusing capacity in guinea pigs following long-term maternal exercise. Journal of Developmental Physiology 5, 1-10.

Parizkova, J. (1979). Cardiac microstructure in female and male offspring of exercised rat mothers. Acta Anatomica 104, 382-387.

Pinto, M. L. \& Shetty, P. S. (1990). Increased maternal physical activity influences birth weight and weight gain of litters of Wistar rats. In Proceedings of XXIII Annual Meeting of the Nutrition Society of India, 88A (Abstr). Hyderabad: Nutrition Society of India, National Institute of Nutrition.

Pollard, I. (1986). Prenatal stress effects over two generations in rats. Journal of Endocrinology 109, $239-244$.

Rao, B. S. (1980). Effects of disruption of diurnal rhythms in food intake of rats. Indian Journal of Physiology and Pharmacology 24, 170-176.

Schneider, J. E. \& Wae, G. N. (1989). Effects of maternal diet, body weight and body composition on infanticide in Syrian hamsters. Physiology and Behavior 46, 815-821.

Stewart, R. J., Preece, R. F. \& Sheppart, H. G. (1975). Twelve generations of marginal protein deficiency. British Journal of Nutrition 33, 233-253.

Tereda, M. (1974). Effect of physical activity before pregnancy on fetus of mice exercised forcibly during pregnancy. Teratology 10, 141-144.

Treadway, J. L. \& Lederman, S. A. (1986). The effects of exercise on milk yield, milk composition and offspring growth in rats. American Journal of Clinical Nutrition 44, 481-488.

Uriu-Hare, J. Y., Keen, C. L., Applegate, E. A. \& Stern, J. S. (1989). The influence of moderate exercise in diabetic and normal pregnancy on maternal and fetal outcome in the rat. Life Sciences 45, 647-654. 